\title{
The Dynamic Characteristic Experimental Method on the Composite Foundation with Rigid-Flexible Compound Piles*
}

\author{
Jihui Ding ${ }^{1}$, Weiyu Wang ${ }^{2}$, Tuo Zhao ${ }^{2}$, Junhui Feng ${ }^{1}$, Panxing Zhang ${ }^{1}$ \\ ${ }^{1}$ College of Civil Engineering, Hebei University, Baoding, China \\ ${ }^{2}$ Hebei Academy of Building Research, Shijiazhuang, China \\ Email: dingjihui@126.com,weiyu_w@163.com, monkey856@126.com, \\ cxaviervon@gmail.com, 15932239509@163.com
}

Received April 28, 2013; revised May 28, 2013; accepted June 4, 2013

Copyright (C) 2013 Jihui Ding et al. This is an open access article distributed under the Creative Commons Attribution License, which permits unrestricted use, distribution, and reproduction in any medium, provided the original work is properly cited.

\begin{abstract}
Based on the idea of optimization design of pile type, the composite foundations, which include cememt-flyash-gaavel (for short CFG) long piles and cement-soil (for short CS) short piles, and CS piles with CFG core as well, are formed. The method of the site dynamic characteristic tests of the composite foundations is discussed. The test results show that fireworks bomb may replace demolitions as the vibration resource. Vibration time is about $0.1 \mathrm{sec}$. Horizontal vibration major frequency is at $22.476-56.436 \mathrm{~Hz}$, and vertical vibration major frequency is at $15.538-55.884 \mathrm{~Hz}$. The pile arrangements of the composite foundation in the same site have more effect on the acceleration peak value. From the point of vibration, the anti-seismic effect of the CS piles with CFG core is better than others.
\end{abstract}

Keywords: Cement-Soil Piles; Cememt-Flyash-Gaavel Piles; Composite Foundation; Dynamic Characteristic; In-Site Test

\section{Introduction}

The composite foundation is that the part body in the natural ground foundation is reinforced or replaced during the ground treatment, and load is born by reinforced body and soil around pile [1]. The composite foundation with multi-type compound piles are formed by two and more than two kinds of piles. The design methods of the single-type-pile composite foundation have relatively ripe experience, and those of multi-type composite foundation are not perfect. With the rapid development of the economy, the strength, length and bearing capacity of the composite foundation have great enhanced. The original design theories do not meet the needs of design, and dynamic problems of composite foundation also become the concern hot point. It is necessary to introduce antiseismic design on the composite foundation. The dynamic studies of the composite foundation mainly concentrated on the numerical simulation applied finite element method software [2-4]. The dynamic characteristic and its effect factors of CFG pile and CS pile composite

*This work was supported by The Natural Science Foundation of Hebei Province under Grant (No. 2011- E080601). foundation were studied by in-site test of demolitions $[5,6]$. Due to the restriction of the demolitions, the site dynamic characteristic tests of the composite foundations are made by using fireworks bomb as driven vibration to replace demolition.

\section{The Introduction of the Test Site}

The test site is located in Shijiazhuang Heibei province. In the $20 \mathrm{~m}$ depth, the soil layers mainly are yellow silt clay, fine sand, middle sand and silt clay. In the $20 \mathrm{~m}$ driving depth, the underwater is not seen. There is not the harmful geologic action in the site. The main parameters of soil layer as shown in Table 1.

Table 1. The main parameters of soil layer of the test site.

\begin{tabular}{cccc}
\hline $\begin{array}{c}\text { Name of the } \\
\text { soil layer }\end{array}$ & $\begin{array}{c}\text { Thickness of } \\
\text { the soil layer } / \mathrm{m}\end{array}$ & $\begin{array}{c}\text { Bearing capacity } \\
f_{a k} / \mathrm{kPa}\end{array}$ & $\begin{array}{c}\text { Modulus } \\
E_{S} / \mathrm{MPa}\end{array}$ \\
\hline 1) Silt clay & 0.5 & 130 & 6.17 \\
2) Fine sand & 1.5 & 140 & 10 \\
3) Middle sand & 4.0 & 200 & 11.5 \\
4) Silt clay & & 270 & 5.84 \\
\hline
\end{tabular}




\section{Model Test and Scheme of the Site}

The three types of the composite foundation model are designed. There are CFG piles, CFG long piles and CS short piles, and CS piles with CFG core as well. The design parameters of the composite foundation are shown in Table 2. The arrangement of the piles and measuring elements of the composite foundation with CFG long piles and CS short piles are shown in Figure 1, those of the composite foundation with CS piles with CFG core are shown in Figure 2, and those of the composite foundation with CFG piles are similar Figure 2. The CFG piles are made by concrete C20, the ratio of the cement and soil of the CS piles is 1:7. The fireworks bomb is used as vibration recourse. The vibration is picked by acceleration sensors.

\section{Analysis on the Dynamic Characteristic of the Composite Foundation}

Through the in-site dynamic characteristic tests of the composite foundation, the dynamic characteristic and its effect factors are studied to supply the theoretical basis of the anti-seismic design.

\subsection{Vibration Acting Time}

The four measuring points are arranged along pile body and one measuring point on the soil between the piles. Every measuring point is differently arranged horizontal and vertical acceleration sensors. The horizontal distance of vibration resources is differently $3 \mathrm{~m}$ and $8 \mathrm{~m}$ at a distance from of the edge of the composite foundation, and the vertical distance is $4.5 \mathrm{~m}$. The typical accelerationtime curve is shown in Figure 3. The vibration acting time is about $1.0 \mathrm{sec}$. The vibration signals are more remarkable.

\subsection{The Main Frequency of Vibration}

Figure 4 is the typical curves of FFT analysis when the vibration resource is $3 \mathrm{~m}$ at a distance from of the edge of the composite foundation with CFG long piles and CS short piles. Through the FFT analysis, the main frequencies of the vibration of the measuring points are shown in Tables 3 and 4 . The measuring results show that main frequency of the horizontal vibration is at 22.476 $56.436 \mathrm{~Hz}$, and main frequency of the vertical vibration is at $15.538-55.884 \mathrm{~Hz}$.

\subsection{Peak Acceleration Results}

The peak acceleration distribution along the pile body when changed the places of the vibration resources is shown in Figures 5-8. When the buried depth of vibration resource, nearer is horizontal distance of the vibration resource from the edge of the composite foundation,
Table 2. The design parameters of the composite foundation.

\begin{tabular}{cccccc}
\hline Model & Type & Symbol & $\begin{array}{c}\text { Pile } \\
\text { length } \\
/ \mathrm{m}\end{array}$ & $\begin{array}{c}\text { Pile } \\
\text { diameter/mm }\end{array}$ & $\begin{array}{c}\text { Pile space } \\
\text { /mm }\end{array}$ \\
\hline Model 1 & CFG pile & CFG & 6.0 & 350 & 100 \\
\multirow{2}{*}{ Model 2 2} & $\begin{array}{c}\text { CF long pile } \\
\text { and } \\
\end{array}$ & CFGL & 6.0 & 350 & 200 \\
\multirow{2}{*}{ Model 3 3 chort pile } & CSS & 4.0 & 350 & 200 \\
& CS pile with & CFGC & 4.0 & 110 & 100 \\
\hline
\end{tabular}

Table 3. The main frequencies of the horizontal vibration /Hz.

\begin{tabular}{ccccc}
\hline$z / L$ & CFG_8 m & CSS_8 m & CFGL_8 m & CFGC_3 m \\
\hline 1 & 37.510 & 47.252 & 37.168 & 37.868 \\
$2 / 3$ & 22.657 & 46.014 & 22.476 & 38.182 \\
$1 / 3$ & 40.542 & 49.539 & 42.167 & 23.636 \\
0 & 33.541 & 51.879 & 48.623 & 27.273 \\
\hline$z / L$ & CFG_3 m & CSS_3 m & CFGL_3 m & \\
\hline 1 & 35.676 & 56.03 & 32.354 & \\
$2 / 3$ & 32.03 & 55.44 & 24.957 & \\
$1 / 3$ & 51.78 & 56.436 & 23.059 & \\
0 & 26.291 & 55.141 & 47.71 & \\
\hline
\end{tabular}

Table 4. The main frequencies of the vertical vibration/Hz.

\begin{tabular}{ccccc}
\hline$z / L$ & CFG_8 m & CSS_8 m & CFGL_8 m & CFGC_3 m \\
\hline 1 & 40.073 & 55.884 & 15.635 & 38.204 \\
$2 / 3$ & 37.226 & 54.091 & 15.612 & 37.835 \\
$1 / 3$ & 37.232 & 55.884 & 15.538 & 16.543 \\
0 & 39.843 & 54.527 & 20.320 & 37.569 \\
$z / L$ & CFG_3 m & CSS_3 m & CFGL_3 m & \\
1 & 23.573 & 47.248 & 23.010 & \\
$2 / 3$ & 23.725 & 48.128 & 23.001 & \\
$1 / 3$ & 23.710 & 36.392 & 23.113 & \\
0 & 31.451 & 48.698 & 22.754 & \\
\hline
\end{tabular}

Note: which $z$ is the buried depth of the measuring point; $L$ is the pile length, and $L=6 \mathrm{~m}$.

larger is the peak acceleration distribution.

From Figure 5, the peak acceleration maximum of the composite foundation of CFG piles occurs in pile top, when the vibration resource is $3 \mathrm{~m}$, and the horizontal and vertical vibration peak accelerations are respectively $4.94 \mathrm{~m} / \mathrm{s}^{2}$ and $1.06 \mathrm{~m} / \mathrm{s}^{2}$, and the ratio is 4.67 ; while the vibration resource is $8 \mathrm{~m}$, and he horizontal and vertical vibration peak accelerations are respectively $1.82 \mathrm{~m} / \mathrm{s}^{2}$ and $0.79 \mathrm{~m} / \mathrm{s}^{2}$, and the ratio is 2.31 .

From Figure 6, the peak acceleration maximum along the CS short pile in the composite foundation of CFG 


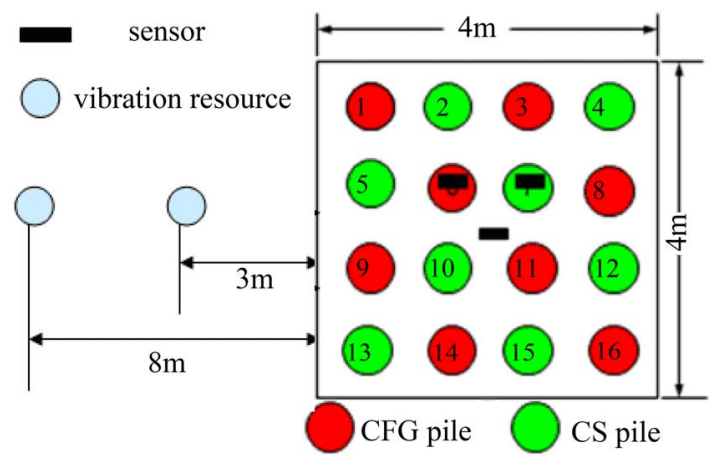

(a)

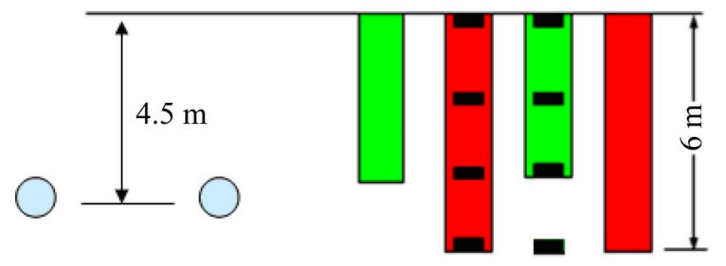

(b)

Figure 1. The arrangement of the piles and measuring elements of the Model 2. (a) Plane arrangement; (b) Profile arrangement.

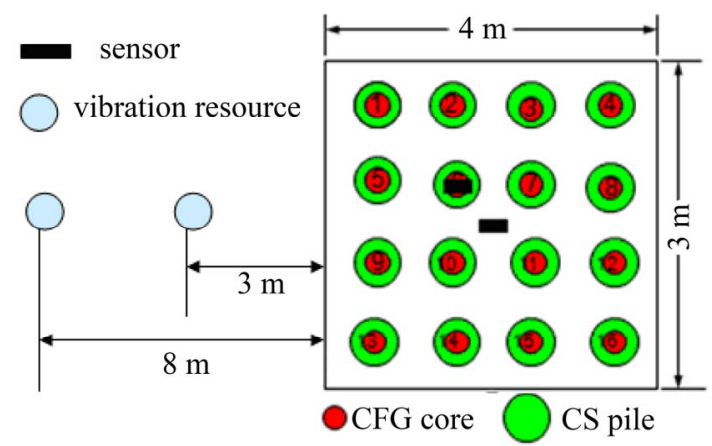

(a)

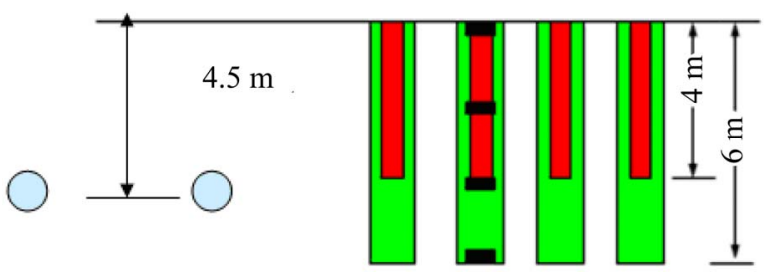

(b)

Figure 2. The arrangement of the piles and measuring elements of the Model 3. (a) Plane arrangement; (b) Profile arrangement.

long piles and CS short piles occurs at $z / L=1$ in pile bottom, when the vibration resource is $3 \mathrm{~m}$, and the horizontal and vertical vibration peak accelerations are respectively $8.20 \mathrm{~m} / \mathrm{s}^{2}$ and $8.34 \mathrm{~m} / \mathrm{s}^{2}$, and the ratio is near 1.0 ; while the vibration resource is $8 \mathrm{~m}$, and the horizontal and vertical vibration peak accelerations are respectively $1.82 \mathrm{~m} / \mathrm{s}^{2}$ and $0.79 \mathrm{~m} / \mathrm{s}^{2}$, and the ratio is 2.31 .

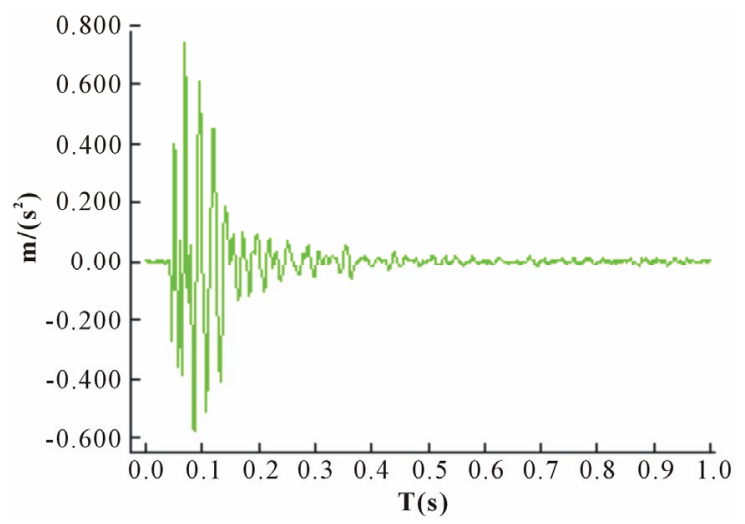

(a)

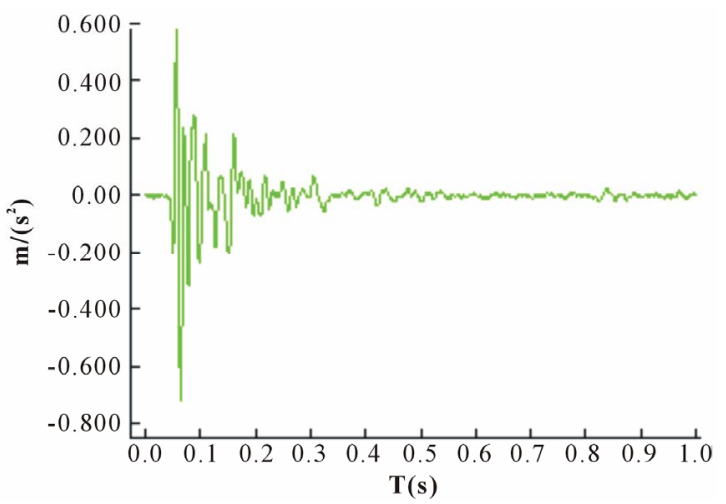

(b)

Figure 3. When the distance of the vibration resource is $8 \mathrm{~m}$, the typical acceleration-time curve along CFG pile body. (a) When measuring point is $6 \mathrm{~m}$ below ground surface, acceleration-time curve of horizontal vibration; (b) When measuring point is $6 \mathrm{~m}$ below ground surface, acceleration-time curve of vertical vibration.

From Figure 7, the peak acceleration maximum along the CFG long pile in the composite foundation of CFG long piles and CS short piles occurs in pile top, when the vibration resource is $3 \mathrm{~m}$, and the horizontal and vertical vibration peak accelerations are respectively $2.83 \mathrm{~m} / \mathrm{s}^{2}$ and $2.42 \mathrm{~m} / \mathrm{s}^{2}$; while the vibration resource is $8 \mathrm{~m}$, and the horizontal and vertical vibration peak accelerations are respectively $1.73 \mathrm{~m} / \mathrm{s}^{2}$ and $1.753 \mathrm{~m} / \mathrm{s}^{2}$.

From Figure 8, the peak acceleration maximum along the pile body in the composite foundation of CS pile with CFG core occurs in pile bottom, when the vibration resource is $3 \mathrm{~m}$, and the horizontal and vertical vibration peak accelerations are respectively $1.93 \mathrm{~m} / \mathrm{s}^{2}$ and 1.62 $\mathrm{m} / \mathrm{s}^{2}$; while the vibration resource is $8 \mathrm{~m}$, and the horizontal and vertical vibration peak accelerations are respectively $1.01 \mathrm{~m} / \mathrm{s}^{2}$ and $1.10 \mathrm{~m} / \mathrm{s}^{2}$. The peak acceleration maximum along pile body is depanded pile arrangements. The place of vibration resource has great effects on peak acceleration maximum along pile body.

The peak acceleration distribution along the pile body when the vibration resource is at $3 \mathrm{~m}$ is shown in Figures 


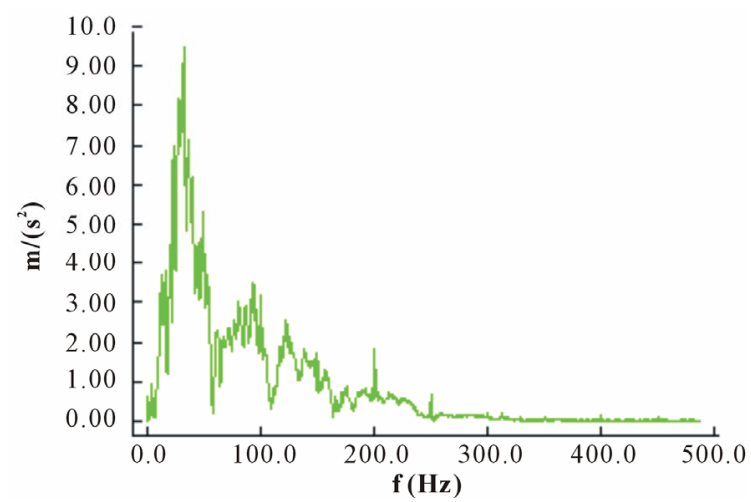

(a)

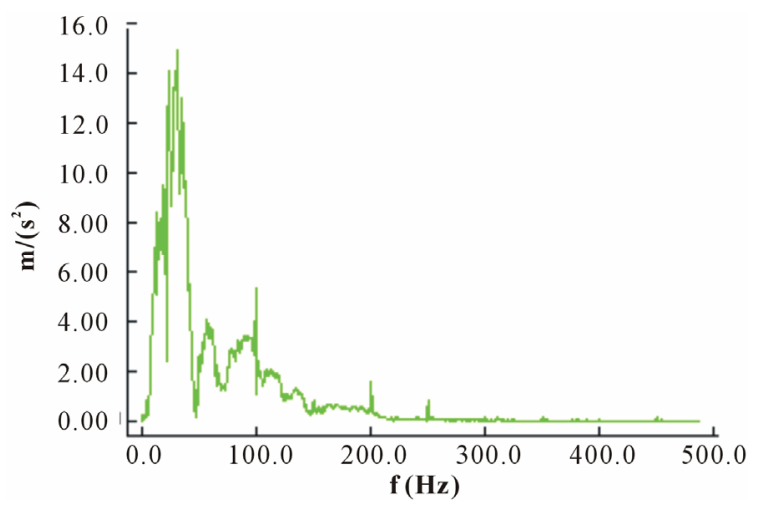

(b)

Figure 4. When the distance of the vibration resource is $\mathbf{3} \mathbf{~ m}$, the typical FFT analysis curve of the composite foundation with CFG long piles and CS short piles. (a) When measuring point is $6 \mathrm{~m}$ below ground surface, acceleration-time curve of horizontal vibration; (b) When measuring point is $6 \mathbf{m}$ below ground surface, acceleration-time curve of vertical vibration.

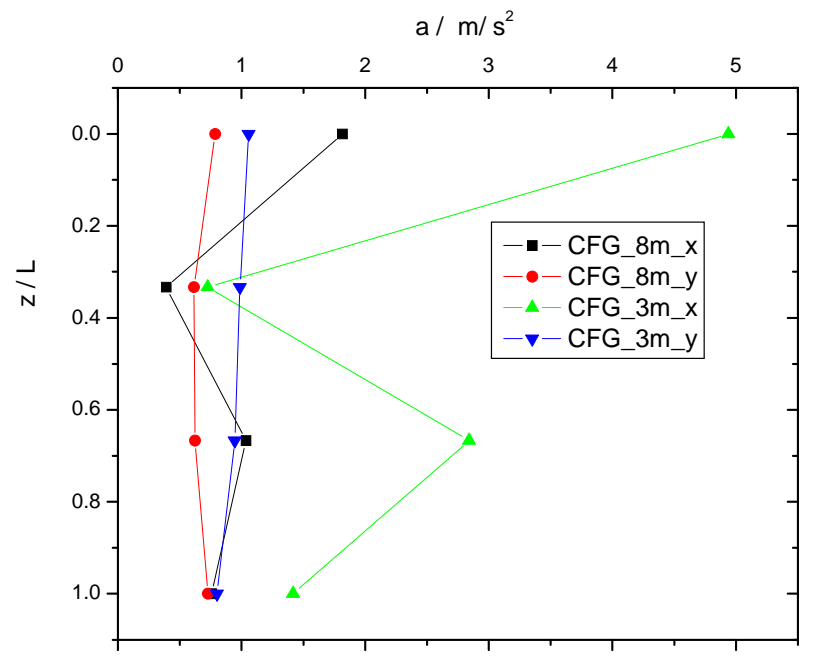

Figure 5. The peak acceleration along the CFG pile.

9 and 10. From Figures 9 and 10, the rigidity of the composite foundation of the CFG long piles and CS short piles is smallest among the three-type composite founda-

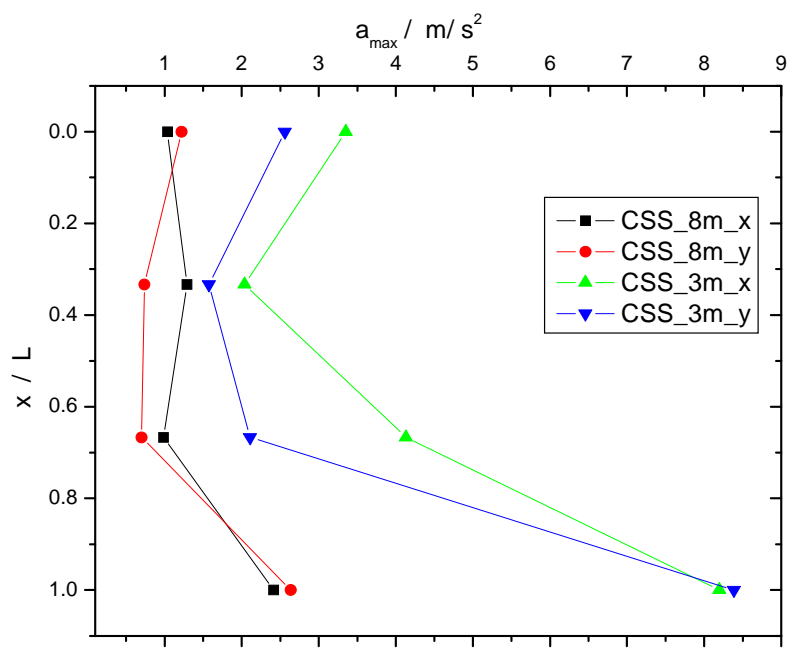

Figure 6. The peak acceleration along the CS short pile.

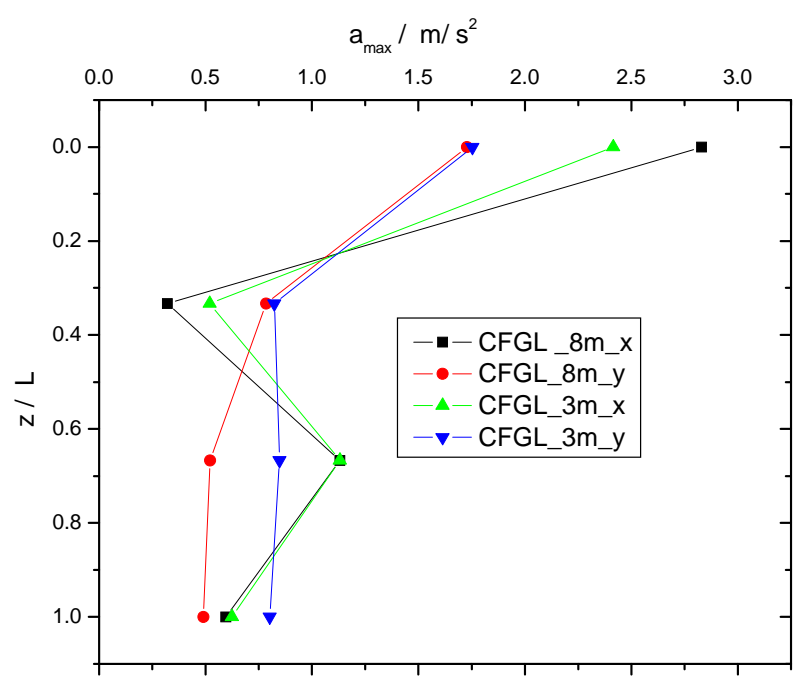

Figure 7. The peak acceleration along the CFG long pile.

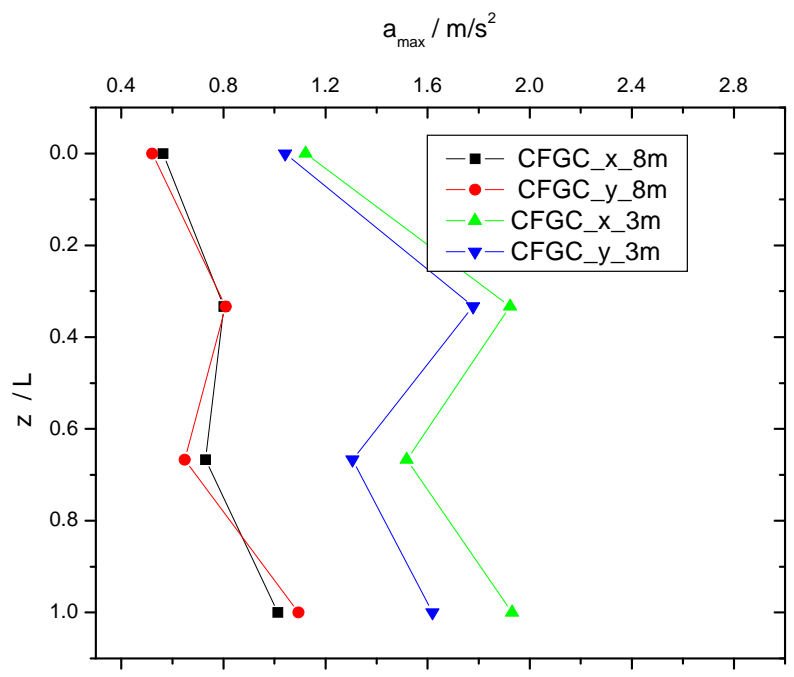

Figure 8. The peak acceleration along the CS pile with CFG core. 


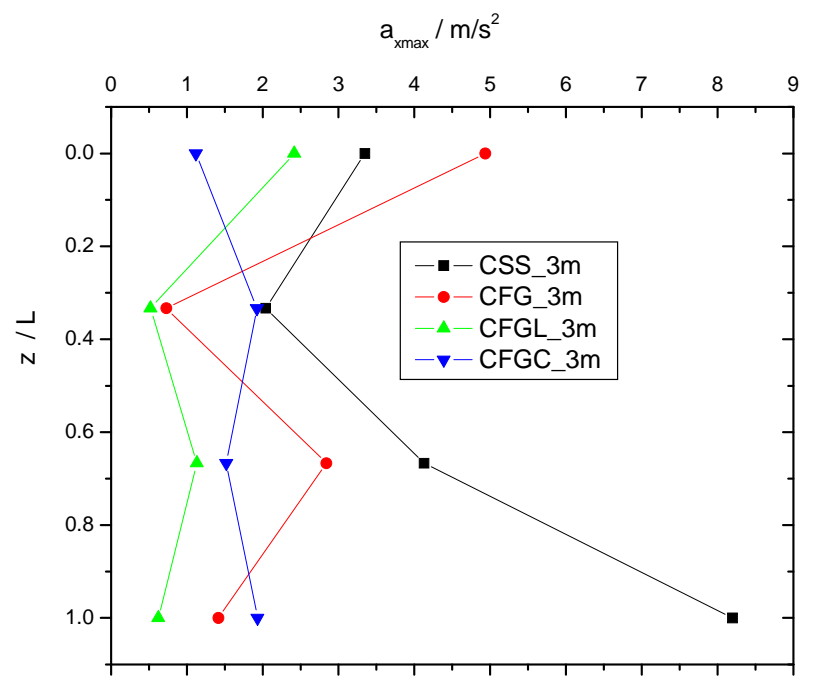

Figure 9. The horizontal peak acceleration along pile.

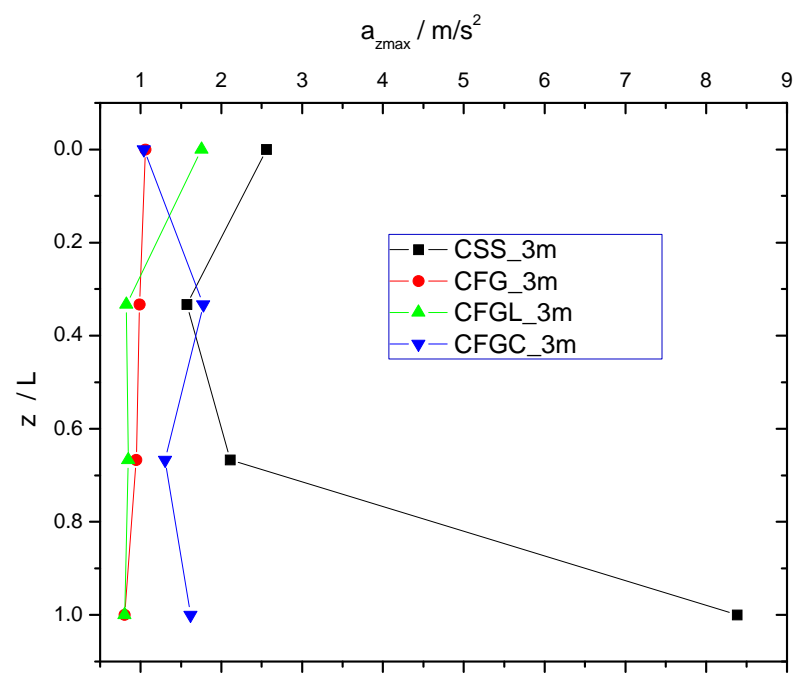

Figure 10. The vertical peak acceleration along pile.

tions, the peak acceleration of the measuring point is largest. From the point of vibration, the peak acceleration of the CS pile with CFG core of the measuring point is uniform along the pile body, the anti-seismic effect CS piles with CFG core is better than others.

\section{Conclusions}

Based on the idea of optimization design of pile type, the composite foundations, which include CFG long piles and CS short piles, and CS piles with CFG core as well, are made. The site dynamic characteristic tests of the composite foundations shows that fireworks bomb may replace demolitions as the vibration resource. Vibration time is about $0.1 \mathrm{sec}$. Horizontal vibration major frequency is at $22.476-56.436 \mathrm{~Hz}$ and vertical vibration major frequency is at 15.538 - $55.884 \mathrm{~Hz}$. The pile arrangement in the composite foundation and position of the vibration resource have a little effects on vibration time and vibration major frequency.

The peak acceleration maximum along pile body is dependent pile arrangements. The place of vibration resource has great effects on peak acceleration maximum along pile body. From the point of vibration, the peak acceleration of the CS pile with CFG core of the measuring point is uniform along the pile body, the anti-seismic effect of the CS piles with CFG core is better than others.

\section{REFERENCES}

[1] China Academy of Building Research "JGJ 79-2002 Technical Code for Ground Treatment of Buildings(s)," China Architecture Industry Press, Beijing, 2002.

[2] J. H. Ding, F. R. Liu, E. X. Du, et al., "Dynamic Characteristic Analysis on Composite Foundation with SoilCement Piles and CFG Piles,” Fly Ash Comprehensive Utilization, Vol. 6, 2008, pp. 37-40.

[3] W. Y. Wang, T. Zhao and Y. J. Meng, "The Numerical Analysis on Bearing Capacity of CFG Pile Composite Foundation under Blasting,” Engineering Mechanics, Vol. 29, No. S1, 2012, pp. 150-155.

[4] J. B. Jiang and S. C. Fu, "Seismic Reaction Analysis of the Composite Foundation,” Bulding Science, Vol. 1, 1996, pp. 23-28.

[5] W. Y. Wang, T. Zhao and J. H. Ding, "Influencing Factors of Dynamic Characteristics and Response of Cement-Fly Ash-Gravel Pile Composite Foundation,” Vol. S2, No. 215, 2010, pp. 115-118.

[6] T. Zhao, C. M. Yang and W. Y. Wang, "The Dynamic Characteristic Test Studies on CFG Pile Composite Foundation under Blasting,” Highway Traffic Science and Technology, Vol. 7, No. 67, 2010, pp. 121-122.. 